\title{
Preface: Targeting the Human Kinome for Cancer Therapy
}

The last 15 years have seen major milestones in kinase research and its translation into the clinic including US Food and Drug Administration approval for the anti-HER2 monoclonal antibody trastuzumab in $1998^{1}$ and for the BCR-ABL-directed tyrosine kinase inhibitor imatinib in 20012; characterization of the human complement of protein kinases or "kinome" $(2002)^{3}$; and the identification and clinical validation of additional kinase drug targets in human cancer that include the epidermal growth factor receptor (EGFR $)^{4}$ and, more recently, mutant BRAF. ${ }^{5}$ Currently, many kinase-directed cancer therapies are being evaluated in clinical trials. However, it is becoming increasingly apparent that the human kinome has much more to offer in terms of potential cancer drug targets. The aim of this issue is to review progress in therapeutic targeting of specific protein kinases that contribute to cancer development and progression and to give a perspective of how this field may develop in the near future. The order and nature of the individual reviews reflect the stage of clinical development achieved by therapies directed against a particular kinase target. Opening the issue are 2 articles about targeting HER2 and BCR-ABL, respectively, and, given that trastuzumab and imatinib both have been in clinical use for more than a decade, these articles focus mainly on the mechanisms underpinning resistance to targeted therapy and identification of predictive biomarkers of response. Following these, 5 reviews discuss particular targeted therapies that progressed into the clinic after 2001. These focus on targeting the EGFRs, vascular EGFRs, phosphatidylinositol 3-kinase/AKT/mammalian target of rapamycin, BRAF, and ALK and review the different types of therapeutic agents employed against these kinases, the development of resistance to these agents, and how to optimize selection of patients for therapy. The next reviews cover therapeutic targeting of Src, insulin-like growth factor-1 receptor, cyclindependent kinases, and FLT3 and Eph receptors. Here, the associated targeted therapies are at an earlier stage of development and are undergoing clinical trials. The final "perspectives" article considers the untapped potential of the kinome for discovery of therapeutic targets, current trends in the development of novel targeted (and multitargeted) therapies, and how the transition of such therapies into effective clinical use can be accelerated.

Guest Editor: Roger J. Daly, Ph.D.

Cancer Research Program, Garvan Institute of Medical Research

Sydney, New South Wales, Australia

and

Department of Medicine

St. Vincent's Hospital Clinical School

University of New South Wales

Kensington, New South Wales, Australia

\section{REFERENCES}

1. Hudis CA. Trastuzumab--mechanism of action and use in clinical practice. N Engl J Med. 2007;357(1):39-51.

2. Sullivan C, Peng C, Chen Y, Li D, Li S. Targeted therapy of chronic myeloid leukemia. Biochem Pharmacol. 2010;80(5):584-591.

3. Manning G, Whyte DB, Martinez R, Hunter T, Sudarsanam S. The protein kinase complement of the human genome. Science. 2002;298(5600):19121934.

4. Pao W, Chmielecki J. Rational, biologically based treatment of EGFR-mutant non-small-cell lung cancer. Nat Rev Cancer. 2010;10(11):760-774.

5. Chapman PB, Hauschild A, Robert C, Haanen JB, Ascierto P, Larkin J, Dummer R, Garbe C, Testori A, Maio M, Hogg D, Lorigan P, Lebbe C, Jouary T, Schadendorf D, Ribas A, O'Day SJ, Sosman JA, Kirkwood JM, Eggermont AM, Dreno B, Nolop K, Li J, Nelson B, Hou J, Lee RJ, Flaherty KT, McArthur GA. Improved survival with vemurafenib in melanoma with BRAF V600E mutation. N Engl J Med. 2011;364(26):2507-2516. 